\title{
CORRECTIONS
}

\section{Publisher Correction: Tissue clearing and its applications in neuroscience}

Hiroki R. Ueda(D), Ali Ertürk(D), Kwanghun Chung (D), Viviana Gradinaru (D, Alain Chédotal(D), Pavel Tomancak and Philipp J. KelleriD

Nature Reviews Neuroscience (2020) https://doi.org/10.1038/s41583-019-0250-1 Published online 2 January 2020

In this Review Article, the accept date was inadvertently omitted. It should be 18 November 2019. This error has been corrected online.

https://doi.org/10.1038/s41583-020-0291-5 I Published online 9 March 2020

(C) Springer Nature Limited 2020

\section{Author Correction: Systemic factors as mediators of brain homeostasis, ageing and neurodegeneration}

John V. Pluvinage and Tony Wyss-Coray (D)

Nature Reviews Neuroscience (2020) https://doi.org/10.1038/s41583-019-0255-9 Published online 8 January 2020

In the originally published version of this article, the competing interests statement indicated that the authors had no competing interests; however, this statement was incorrect. The statement should have read as follows: 'T.W.-C. is a co-founder, shareholder and paid consultant of Alkahest, Inc., a company that develops treatments for CNS diseases based on the concept that circulatory factors regulate brain function. J.V.P. declares no competing interests.' This error has been corrected in the HTML and PDF versions of the article.

https://doi.org/10.1038/s41583-020-0293-3 I Published online 13 March 2020

This is a U.S. government work and not under copyright protection in the U.S.; foreign copyright protection may apply 2020 